\title{
RELATIONSHIP BETWEEN OCCLUSAL PLANE ORIENTATION AND SAGITTAL MALOCCLUSIONS: STUDY OF AN ORTHODONTIC POPULATION
}

\author{
INES DALLEL ${ }^{1 *}$, SANA KANOUN ${ }^{2}$, MARIEM NAHDI ${ }^{3}$, MONCEF OMMEZINE ${ }^{4}$, SAMIR TOBJI $^{1}$, ADEL BEN AMOR ${ }^{1}$ \\ ${ }^{1}$ Department of Dento-Facial Orthopedics, University of Monastir, Faculty of Dental Medicine, Monastir Dental Clinic, Laboratory of \\ Oral Health and Orofacial Rehabilitation, LR12ES11, 5000 Monastir, Tunisia. ${ }^{2}$ Faculty of Dental Medicine, University of Monastir, 5000 \\ Monastir, Tunisia. ${ }^{3}$ Doctor -private practice. ${ }^{4}$ Faculty of Dental Medicine, University of Monastir, Laboratory of Oral Health and Orofacial \\ Rehabilitation, LR12ES11, 5000 Monastir, Tunisia. Email: dr.ines.dalel@gmail.com
}

Received: 10 February 2021, Revised and Accepted: 05 April 2021

\section{ABSTRACT}

Objective: The aim of this study was to evaluate the association of the skeletal pattern and angle class with the occlusal plane (OP). This study also examined the effect of orthodontic treatment on this plane.

Methods: Lateral cephalometric radiographs of a sample of 135 patients were collected. The angles between the Frankfort horizontal, palatal plane (PP), mandibular plane (MP), and the OP were analyzed and compared between several groups and subsequently before and after treatment.

Results: The statistical comparison between 3 skeletal frame groups demonstrates that the cant of the OP showed a major difference. This difference was greater in class III subjects. Examination revealed that the OP was not meaningfully affected within the Angle classification. Statistically, a significant correlation was found between OP steepness and the vertical skeletal pattern. A significant rise of OP/sella-nasion (SN) for class I ( $\mathrm{p}=0.019$ ) and II ( $\mathrm{p}=0.015)$ after orthodontic treatment. In addition, patients treated with elastics showed a significant decrease of OP/MP (mandibular plane) in Angle class III and considerable increase of OP/SN and OP/PP in Angle class II. Observations of the group treated with bimaxillary extractions showed that OP/SN (sella nasion line) and OP/PP differ in a meaningful way.

Conclusion: This study confirms the association between the skeletal pattern and the OP inclination in adults. Concerning the Angle classification, there was no significant difference between the groups. Orthodontic therapy had an influence on the inclination of this plane for the different malocclusions. Premolars extraction in class I cases significantly modified the OP. For class II and III malocclusions, the OP inclination was mainly altered by the use of intermaxillary traction elastics.

Keywords: Orthodontics, Occlusion, Occlusal plane, Malocclusion, Angle classification.

(C) 2021 The Authors. Published by Innovare Academic Sciences Pvt Ltd. This is an open access article under the CC BY license (http://creativecommons.org/ licenses/by/4.0/) DOI: http://dx.doi.org/10.22159/ijss.2021v9i3.41058. Journal homepage: https://innovareacademics.in/journals/index.php/ijss

\section{INTRODUCTION}

Maintaining the mandatory function is a major priority in orthodontic treatment. To achieve this aim, an important parameter has to be considered: the occlusal plane (OP). It is a diagnosis element, a tool in treatment follow-up and a major factor in post-treatment evaluation [1].

The previous studies assess the relationship between the inclination of the $\mathrm{OP}$ and the skeletal pattern. However, the relation with the Angle classification has not been taken into consideration [2,3]. Furthermore, no other study has tested the variation of the OP after the orthodontic treatment.

Therefore, the aims of this study are to analyze the relationship of the inclination of the OP with the skeletal pattern and the Angle class and to evaluate this inclination submitted to the effect of orthodontic treatment Wich consist the originality of this work

The goal is essentially to optimize the manducatory functions and to maintain a healthy and functional dental system over time.

\section{MATERIALS AND METHODS}

The sample of the current retrospective study was collected from the patients' archives of the dental clinic of Monastir, Tunisia. The total sample comprised 135 subjects selected using random sampling procedures. It is based on the availability of lateral cephalograms, orthopantomograms, intra- and extra-oral photograph, as well as medical examination documents under the following inclusion criteria: 17 years and older, at the end of growth period, complete permanent dentition (third molar not included) and no former orthodontic treatment.

Exclusion criteria are asymmetric malocclusion (class II subdivision right or left or class II associated to a class III), cleft lip and cleft palate patients, dental agenesis, oligodontia, craniofacial abnormality (or related to a congenital syndrome), previous orthodontics or orthognathic surgery, prosthetic restoration with fixed or partial dentures or implants, temporomandibular joint disorder, and facial asymmetry.

Cephalograms were analyzed before and after orthodontic treatment and one operator made manual cephalometric tracings of the skull radiographs on acetate sheets with a drop-action pencil (lead width $0.5 \mathrm{~mm}$ ). The light table was located in a silent, dimmed investigation room.

As shown in Fig. 1, the operator identified sella-nasion (SN), Frankfort horizontal, the palatal plane (PP) from anterior nasal spine to posterior nasal spine, and the mandibular plane (MP) from tangential gonion to chin.

The bisector OP was traced by averaging the incisor and permanent first molars overbite.

The analyzed angular measurements are shown in the Table 1.

Statistical analysis

This statistical analysis was performed with SPSS for Windows program $\left(\right.$ IBM $^{\circledR}$ SPSS $^{\circledR}$ statistics version 20). In addition to standard descriptive statistical calculations (means and standard deviations), Chi-square 


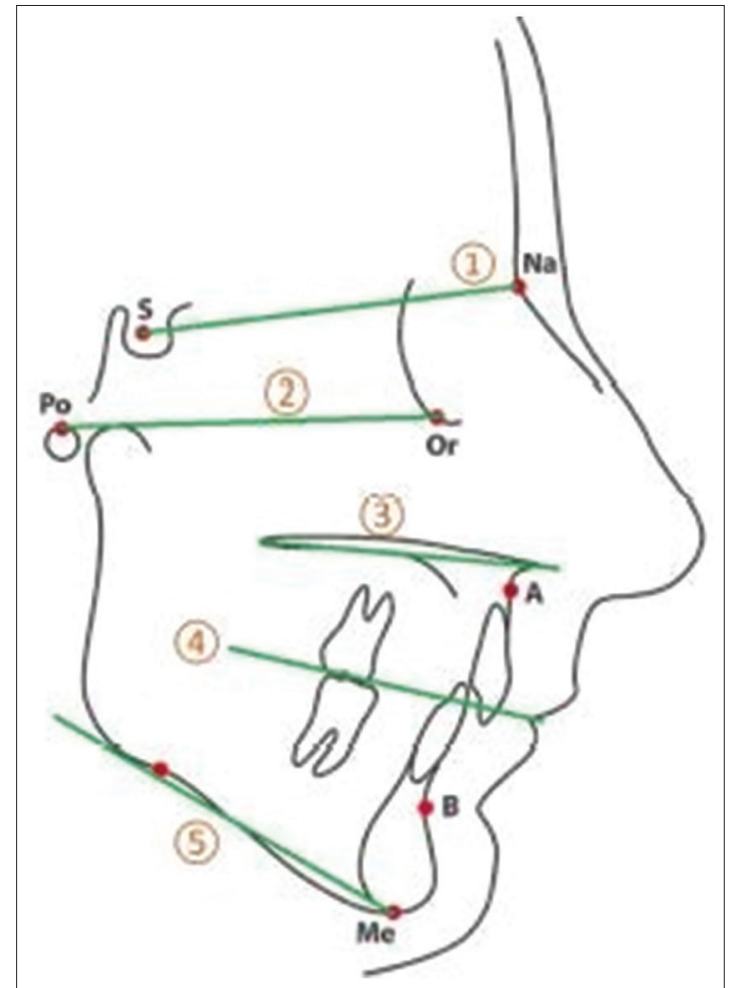

Fig. 1: Illustration of the cephalometric tracings. (1) Sella-nasion line (2) Frankfort horizontal (3) palatal plane (4) occlusal plane (5) mandibular plane. Me (Menton): The most inferior pointof the chin, A: point $A$ - The deepest point in the curvature of the maxillary alveolar process; B: point $B$ - The deepest point in the curvature of the mandibular alveolar process

test was used to compare means. The statically significant levels were predetermined at $\mathrm{p}=0.05$. The one-way analysis of variance ANOVA test was used to determine statistically significant differences between groups

The least significant difference test was also performed for multiple group comparisons to determine which group significantly differed. The paired two-sample t-test was used to compare means before and after treatment.

\section{RESULTS}

The sample's age ranged from 17 to 54 years (average 20.86 \pm 4.58 years), comprising $15.6 \%$ male and $84.4 \%$ females. About $44.4 \%$ of the individuals were Angle class I, 31.9\% Angle class II, and 23.7\% Angle class III.

Of the total sample of subjects, $53.3 \%$ were classified in skeletal Class I, $34.8 \%$ in Class II, and $11.9 \%$ in Class III, $14.1 \%$ short face height, $51.1 \%$ had normal face height, and 34.8\% patients long face height (Table 1).

All statistical data relating measurements such as means, standard deviation, and ranges are presented in Table 2 .

In the first part of the study, we assessed the relationship between the OP inclination and 3 parameters: Skeletal class, Angle class, and vertical parameter. The statistical comparison between 3 skeletal frame groups is shown in Table 3.

The values of OP/SN1 and OP/PP1 indicated a meaningful difference between the 3 groups ( $<<0.001$ for OP/SN1 and $p=0.003$ for OP/PP1). The tests revealed that difference was substantially higher between class I and class III also class II and class III. In contrast, no significant difference was found between class I and class II. The analysis of OP/ PM1 did not show any valuable difference between the skeletal groups
Table 1: Variables measured from lateral cephalograms

\begin{tabular}{ll}
\hline Variable & Description \\
\hline SNA & Angle formed by SN and NA planes \\
SNB & Angle formed by SN and NB planes \\
AoBo & Projection of A and B on occlusal plane \\
MP/SN & Angle formed by MP and SN \\
HFP & Posterior facial height \\
HFA & Anterior facial height \\
IF & Facial index \\
OP/SN & Angle formed by OP and SN \\
OP/PP & Angle formed by PP and OP \\
OP/MP & Angle formed by OP and MP \\
\hline
\end{tabular}

Table 2: Descriptive statistics of quantitative variables ( $n=135)$

\begin{tabular}{|c|c|c|c|c|}
\hline & Minimum & Maximum & Mean & SD \\
\hline Age & 17 & 54 & 20.86 & 4.58 \\
\hline SNA1 $\left(^{\circ}\right)$ & 70 & 89 & 79.82 & 3.93 \\
\hline SNB1 $\left(^{\circ}\right)$ & 64 & 87 & 76.67 & 4.25 \\
\hline ANB1 $\left(^{\circ}\right)$ & -7 & 9.5 & 3.18 & 2.80 \\
\hline AoBo1 (mm) & -11 & 11.5 & 0.24 & 4.13 \\
\hline $\mathrm{MP} / \mathrm{SN} 1\left(^{\circ}\right)$ & 20 & 54 & 34.88 & 6.83 \\
\hline HFP1 (mm) & 30 & 58.5 & 45.70 & 5.50 \\
\hline HFA1 (mm) & 48 & 85 & 66.69 & 7.05 \\
\hline IF1 & 0.64 & 0.89 & 0.68 & 0.07 \\
\hline OP/SN1 $\left(^{\circ}\right)$ & 4 & 30 & 17.02 & 4.78 \\
\hline OP/PP1 $\left(^{\circ}\right)$ & -6 & 18 & 7.76 & 4.33 \\
\hline $\mathrm{OP} / \mathrm{MP} 1\left(^{\circ}\right)$ & 3 & 29.5 & 17.20 & 4.73 \\
\hline SNA2 $\left(^{\circ}\right)$ & 68 & 88 & 79.54 & 3.99 \\
\hline SNB2 $\left(^{\circ}\right)$ & 65.5 & 87 & 76.13 & 4.12 \\
\hline ANB2 $\left(^{\circ}\right)$ & -2 & 8 & 3.44 & 2.39 \\
\hline AoBo2 (mm) & -13 & 8 & 0.17 & 3.36 \\
\hline $\mathrm{MP} / \mathrm{SN} 2\left(^{\circ}\right)$ & 19.5 & 52.5 & 35.41 & 6.77 \\
\hline HFP2 (mm) & 33 & 57 & 44.87 & 5.05 \\
\hline HFA2 (mm) & 40.5 & 86 & 66.14 & 7.38 \\
\hline IF2 & 0.5 & 0.9 & 0.67 & 0.07 \\
\hline $\mathrm{OP} / \mathrm{SN} 2\left(^{\circ}\right)$ & 6 & 30.5 & 17.88 & 4.77 \\
\hline $\mathrm{OP} / \mathrm{PP} 2\left(^{\circ}\right)$ & -3 & 18.5 & 8.42 & 4.02 \\
\hline $\mathrm{OP} / \mathrm{MP} 2\left(^{\circ}\right)$ & 2 & 29 & 17.26 & 4.72 \\
\hline
\end{tabular}

The index " 1 " attributed to the variables before treatment . The index " 2 " attributed to the variables after treatment.

(Table 4). Further examination revealed that OP/SN1, OP/PP1, and OP/ PM1 were not significantly different within the Angle classification. Comparison between pairs of groups showed a striking difference between class I and class III ( $p=0041)$ and reaching significance when class II and class III were compared ( $\mathrm{p}=0.061$ ). No major difference was observed for class II division 1 or 2 (Table 3).

PO/SN1, PO/PP1, and P0/PM1 vary in an important way depending on the vertical skeletal pattern (Table 4). However, PO/SN1 and PO/PP1 did not show a significant difference depending on the vertical type of occlusion. In addition, there was a major disparity of OP/PM1 between 3 groups (open bite, deep bite, and normal bite depth). This difference is more significant between groups showing deep bite and normal bite also between groups showing deep-bite and open-bite.

Student t-test was applied for paired simples to compare PO/SN1 and PO/SN2, PO/PP1 and PO/PP2, and PO/PM1 and PO/PM2.

Concerning skeletal groups, significant arise of OP/SN was observed for class I $(\mathrm{p}=0.019)$ and II $(\mathrm{p}=0.015)$ after orthodontic treatment

Significantly, OP/PM was higher only in class II after orthodontic treatment $(\mathrm{p}=0.002)$. In contrast, OP/PM did not show a remarkable change, although it tends to be more important for class III ( $\mathrm{p}=0.071)$.

Concerning class I malocclusion, only $\mathrm{PO} / \mathrm{SN}$ was significantly higher after treatment $(\mathrm{p}=0.021)$. Whereas PO/PM was significantly lower for 
Table 3: ANOVA and LSD tests results describing the influence of skeletal and Angle class on OP/SN1, OP/PP1, and OP/PM1

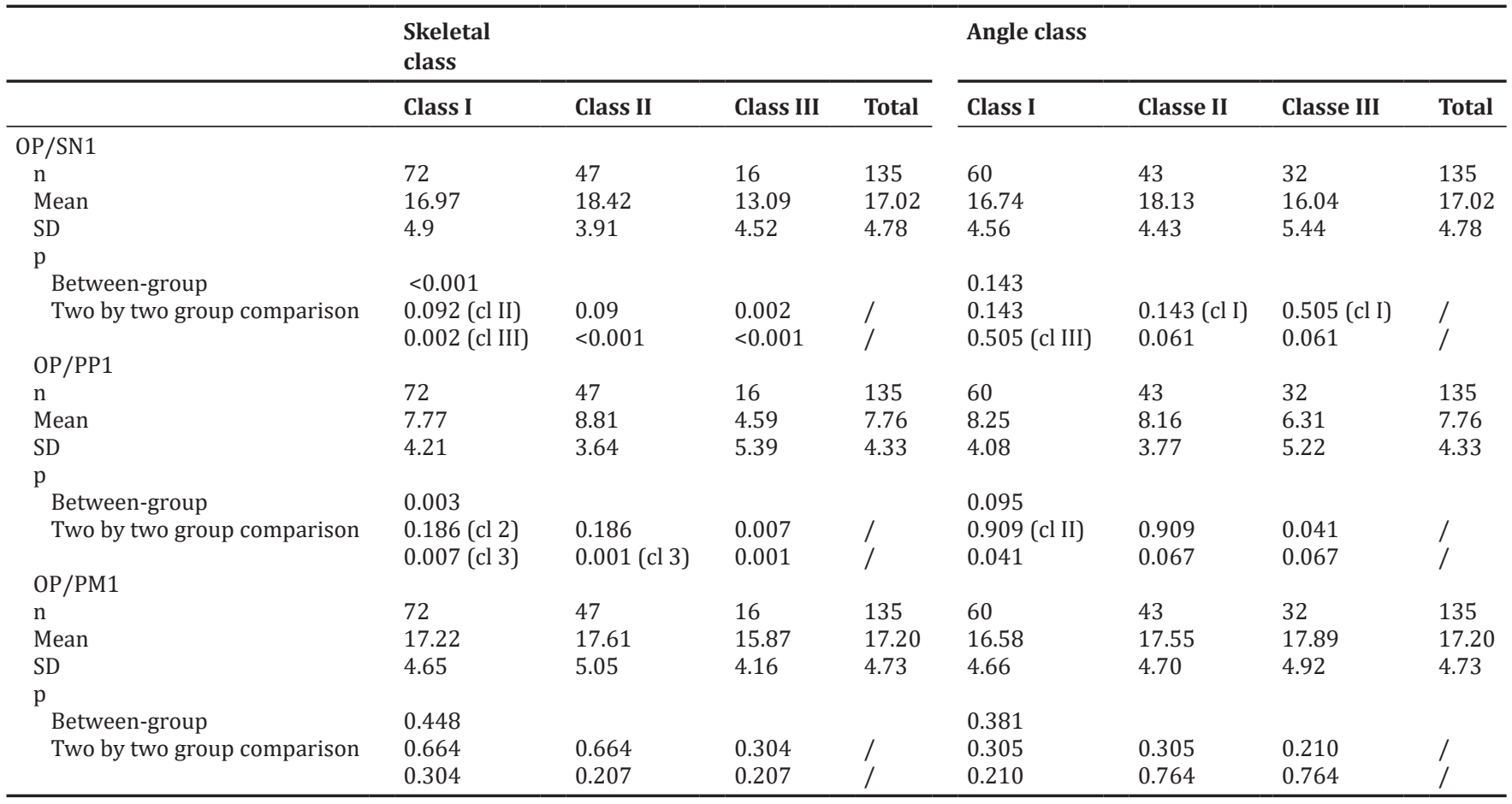

OP/SN1: The angle formed by the lines OP and SN before treatment. OP/PP1:The angle formed by the lines OP and PP before treatment. OP/MP1:The angle formed by the lines OP and MP before treatment. SD: Standard deviation, n: Sample size. ${ }^{*}$ Total sample size $=135$

Table 4: ANOVA and LSD tests results describing the influence of the vertical pattern on OP/SN1, OP/PP1, and OP/PM1

\begin{tabular}{|c|c|c|c|c|c|c|c|c|}
\hline & Skeletal & Occlusion & Skeletal & Occlusion & Skeletal & Occlusion & Skeletal & Occlusion \\
\hline & Short face & Normal & Short face & Normal & Short face & Normal & Short face & Normal \\
\hline \multicolumn{9}{|l|}{ P0/SN1 } \\
\hline $\mathrm{n}$ & 19 & 69 & 47 & 135 & 47 & 39 & 49 & 135 \\
\hline Mean & 12.86 & 15.81 & 20.46 & 17.02 & 17.23 & 16.92 & 16.89 & 17.02 \\
\hline SD & 3.88 & 3.88 & 4.11 & 4.78 & 5.72 & 4.24 & 4.24 & 4.78 \\
\hline \multicolumn{9}{|l|}{$\mathrm{p}$} \\
\hline Between -group & $<0.001$ & & & & 0.932 & & & \\
\hline \multirow[t]{2}{*}{ Two by two group comparison } & 0.005 & 0.005 & $<0.001$ & / & 0.766 & 0.766 & 0.733 & / \\
\hline & $<0.001$ & $<0.001$ & $<0.001$ & / & 0.733 & 0.981 & 0.981 & / \\
\hline \multicolumn{9}{|l|}{ P0/PP1 } \\
\hline $\mathrm{n}$ & 19 & 69 & 47 & 135 & 47 & 39 & 49 & 135 \\
\hline Mean & 4.55 & 6.92 & 10.28 & 7.76 & 7.78 & 7.93 & 7.60 & 7.76 \\
\hline SD & 4.07 & 3.91 & 3.71 & 4.33 & 5.01 & 4.25 & 3.73 & 4.33 \\
\hline \multicolumn{9}{|l|}{$\mathrm{p}$} \\
\hline Between -group & $<0.001$ & & & & 0.937 & & & \\
\hline Two by two group comparison & 0.019 & 0.019 & $<0.001$ & / & 0.875 & 0.875 & 0.836 & / \\
\hline \multicolumn{9}{|l|}{ P0/PM1 } \\
\hline $\mathrm{n}$ & 19 & 69 & 47 & 135 & 47 & 39 & 49 & 135 \\
\hline Mean & 12.10 & 16.19 & 20.74 & 17.20 & 19.58 & 16.85 & 15.19 & 17.20 \\
\hline SD & 4.04 & 3.33 & 4.17 & 4.73 & 4.45 & 4.00 & 4.60 & 4.73 \\
\hline \multicolumn{9}{|l|}{$\mathrm{p}$} \\
\hline Between -group & $<0.001$ & & & & $<0.001$ & & & \\
\hline \multirow[t]{2}{*}{ Two by two group comparison } & $<0.001$ & $<0.001$ & $<0.001$ & / & 0.005 & 0.005 & $<0.001$ & / \\
\hline & $<0.001$ & $<0.001$ & $<0.001$ & / & $<0.001$ & 0.079 & 0.079 & / \\
\hline
\end{tabular}

OP/SN1: The angle formed by the lines OP and SN before treatment. OP/PP1:The angle formed by the lines OP and PP before treatment. OP/MP1:The angle formed by the lines OP and MP before treatment. SD: Standard deviation, n: Sample size. *Total sample size =135

class III ( $\mathrm{p}=0.024)$. Concerning Angle class II, a substantial difference was noticed for all values ( $\mathrm{p}<0.001$ ), especially in class II division 1 . For class II division 2, only PO/SN showed a important change (Table 5).

To study the effect of elastics on $\mathrm{OP}$, the sample was divided into 2 groups: Treated with elastics; group $1(57,7 \%)$ and treated without elastics; group $2(42,2 \%)$.
The group treated with elastics revealed a considerable increase of $\mathrm{OP} /$ $\mathrm{SN}(\mathrm{p}=0.014)$ and OP/PP $(\mathrm{p}=0.002)$.

Our results demonstrate that significant differences concern only class II Angle group. Furthermore, PO/PM showed a substantial decrease for Angle class III patients treated with elastics. Values were approximately the same in the group treated without elastics (Table 6) 
Table 5: Comparison of variables OP/SN, OP/PP, and OP/MP before and after treatment according to skeletal and Angle class

\begin{tabular}{|c|c|c|c|c|c|c|}
\hline & $\begin{array}{l}\text { Skeletal } \\
\text { class }\end{array}$ & $\begin{array}{l}\text { Pairs } \\
\text { studied }\end{array}$ & $\mathbf{N}$ & Mean & SD & $\mathbf{p}$ \\
\hline \multirow{18}{*}{$\begin{array}{l}\text { Skeletal } \\
\text { class }\end{array}$} & \multirow[t]{6}{*}{ Class I } & OP/SN1 & \multirow[t]{6}{*}{72} & 16.97 & 4.90 & \multirow[t]{2}{*}{0.019} \\
\hline & & OP/SN2 & & 17.94 & 4.48 & \\
\hline & & OP/PP1 & & 4.21 & 4.21 & \multirow[t]{2}{*}{0.088} \\
\hline & & OP/PP2 & & 3.55 & 3.55 & \\
\hline & & OP/MP1 & & 17.22 & 4.65 & \multirow[t]{2}{*}{0.369} \\
\hline & & OP/MP2 & & 16.94 & 5.22 & \\
\hline & \multirow[t]{6}{*}{ Class II } & OP/SN1 & 47 & 18.42 & 3.91 & \multirow[t]{2}{*}{0.015} \\
\hline & & OP/SN2 & & 19.64 & 3.94 & \\
\hline & & OP/PP1 & & 8.81 & 3.64 & \multirow[t]{2}{*}{0.002} \\
\hline & & OP/PP2 & & 10.04 & 3.54 & \\
\hline & & OP/MP1 & & 17.61 & 5.05 & 0.816 \\
\hline & & OP/MP2 & & 17.52 & 4.28 & \\
\hline & \multirow[t]{6}{*}{ Class III } & OP/SN1 & 16 & 13.09 & 4.52 & \multirow[t]{2}{*}{0.261} \\
\hline & & OP/SN2 & & 12.46 & 4.48 & \\
\hline & & OP/PP1 & & 4.59 & 5.39 & \multirow[t]{2}{*}{0.408} \\
\hline & & OP/PP2 & & 4.12 & 4.30 & \\
\hline & & OP/MP1 & & 15.87 & 4.16 & \multirow[t]{2}{*}{0.071} \\
\hline & & OP/MP2 & & 17.96 & 3.57 & \\
\hline Angle & & OP/SN1 & 60 & 16.74 & 4.56 & 0.021 \\
\hline \multirow[t]{17}{*}{ class } & & $\mathrm{OP} / \mathrm{SN} 2$ & & 17.78 & 4.27 & \\
\hline & & OP/PP1 & & 8.25 & 4.08 & \multirow[t]{2}{*}{0.189} \\
\hline & & OP/PP2 & & 8.66 & 3.96 & \\
\hline & & OP/MP1 & & 16.58 & 16.58 & \multirow[t]{2}{*}{0.919} \\
\hline & & OP/MP2 & & 16.60 & 16.60 & \\
\hline & & OP/SN1 & 43 & 18.13 & 4.43 & \multirow[t]{2}{*}{$<0.001$} \\
\hline & & $\mathrm{OP} / \mathrm{SN} 2$ & & 19.89 & 4.39 & \\
\hline & & OP/PP1 & & 8.16 & 3.77 & \multirow[t]{2}{*}{$<0.001$} \\
\hline & & OP/PP2 & & 9.83 & 3.52 & \\
\hline & & OP/MP1 & & 17.55 & 4.70 & \multirow[t]{2}{*}{0.029} \\
\hline & & OP/MP2 & & 16.50 & 4.47 & \\
\hline & & OP/SN1 & 32 & 16.04 & 5.44 & \multirow[t]{2}{*}{0.290} \\
\hline & & $\mathrm{OP} / \mathrm{SN} 2$ & & 15.39 & 5.06 & \\
\hline & & OP/PP1 & & 6.31 & 5.22 & \multirow[t]{2}{*}{0.654} \\
\hline & & OP/PP2 & & 6.09 & 3.86 & \\
\hline & & OP/MP1 & & 17.89 & 4.92 & \multirow[t]{2}{*}{0.024} \\
\hline & & OP/MP2 & & 19.53 & 4.08 & \\
\hline
\end{tabular}

SD:Standard deviation, n: Sample size, OP: Occlusal plane, SN: Sella- Nasion line, PP: palatal plane, MP: Mandibular plane. Total sample size $=135$

In further examinations, the simple was divided into 3 groups: Treated without extraction (61.5\%), with uni-maxillary extractions $(8.9 \%)$, or bimaxillary extractions (29.6\%). Observations of the group treated with bimaxillary extractions showed that OP/SN $(\mathrm{p}=0.009)$ and OP/PP $(\mathrm{p}=0.007)$ differed in a major way. No significant change was noticed for other groups.

There is a positive correlation between extraction treatment in class II Angle group and steep OP. For the two other groups, the change is not significant. For Angle class I treated with bimaxillary extractions, a major increase of PO/SN was noticed $(\mathrm{p}=0.044)$ and a difference in PO/ PP which tend to be significant $(\mathrm{p}=0.065)$.

\section{DISCUSSION}

The inclination of the OP describes a vertical morphologic trait, which then may affect the anteroposterior skeletal pattern. In the current study, considerable differences of OP/SN1 between groups confirmed what Tovstein [3] Fushima [1], Tanaka and Sato [2], and Celar [4] established about the relationship between OP and sagittal discrepancies. Consequently, steep OP for class II and horizontal OP for class III. The difference was more noticeable between class III and the two other groups. This difference suggests that the inclination of the OP in class I is similar to class II subjects.

Physiological mastication is disturbed in class III malocclusion caused by the pathologic orientation of the OP according to Raymond [5]. Depending
Table 6: Level of significance (p) of pairs of angles $\mathrm{PO} / \mathrm{SN}, \mathrm{PO} /$ $\mathrm{PP}$, and PO/PM depending on treatment type

\begin{tabular}{|c|c|c|c|c|c|}
\hline & Pairs studied & $\mathbf{n}$ & Mean & SD & $\mathbf{p}$ \\
\hline \multirow[t]{6}{*}{ With elastics } & OP/SN1 & 57 & 17.24 & 4.56 & 0.087 \\
\hline & OP/SN2 & & 18.00 & 4.27 & \\
\hline & OP/PP1 & & 8.27 & 4.08 & 0.577 \\
\hline & $\mathrm{OP} / \mathrm{PP} 2$ & & 8.44 & 3.96 & \\
\hline & OP/MP1 & & 17.50 & 4.66 & 0.759 \\
\hline & OP/MP2 & & 17.58 & 5.90 & \\
\hline \multirow{6}{*}{$\begin{array}{l}\text { Without } \\
\text { elastics }\end{array}$} & OP/SN1 & 78 & 16.85 & 4.43 & 0.014 \\
\hline & OP/SN2 & & 17.80 & 4.39 & \\
\hline & OP/PP1 & & 7.39 & 3.77 & 0.002 \\
\hline & OP/PP2 & & 8.41 & 3.52 & \\
\hline & OP/MP1 & & 16.98 & 4.70 & 0.911 \\
\hline & OP/MP2 & & 17.03 & 4.47 & \\
\hline \multirow{6}{*}{$\begin{array}{l}\text { Without } \\
\text { extractions }\end{array}$} & OP/SN1 & 83 & 17.05 & 4.94 & 0.077 \\
\hline & OP/SN2 & & 17.72 & 4.79 & \\
\hline & OP/PP1 & & 7.18 & 4.52 & 0.135 \\
\hline & OP/PP2 & & 7.64 & 4.05 & \\
\hline & OP/MP1 & & 16.15 & 16.15 & 0.737 \\
\hline & OP/MP2 & & 16.83 & 16.83 & \\
\hline \multirow{6}{*}{$\begin{array}{l}\text { With uni- } \\
\text { maxillary } \\
\text { extractions }\end{array}$} & OP/SN1 & 12 & 16.25 & 4.61 & $<0.501$ \\
\hline & OP/SN2 & & 16.83 & 4.78 & \\
\hline & OP/PP1 & & 9.04 & 4.19 & $<0.483$ \\
\hline & $\mathrm{OP} / \mathrm{PP} 2$ & & 9.45 & 4.55 & \\
\hline & OP/MP1 & & 18.58 & 4.96 & 0.357 \\
\hline & OP/MP2 & & 19.54 & 4.03 & \\
\hline \multirow{6}{*}{$\begin{array}{l}\text { With bi- } \\
\text { maxillary } \\
\text { extractions }\end{array}$} & OP/SN1 & 40 & 17.18 & 4.56 & 0.009 \\
\hline & OP/SN2 & & 18.53 & 4.52 & \\
\hline & OP/PP1 & & 8.57 & 3.83 & 0.007 \\
\hline & $\mathrm{OP} / \mathrm{PP} 2$ & & 9.75 & 3.43 & \\
\hline & OP/MP1 & & 18.96 & 4.38 & 0.543 \\
\hline & OP/MP2 & & 18.66 & 4.28 & \\
\hline
\end{tabular}

SD:Standard deviation, n: Sample size, OP: Occlusal plane, SN: Sella- Nasion line, PP: palatal plane, MP: Mandibular plane. Total sample size $=135$

on the gravity of class III, the examination of lateral mandibular movements and protrusion reveals its abnormal orientation. These results added to Tanaka and Sato [2] findings confirm that the cant of the OP plays a crucial role in the establishment of different dentoskeletal frames.

In this present study, we chose to rely on steady structures and precise landmarks: SN [6]. Conversely, to earlier studies that used Frankfort plane as a reference, we also chose to refer our measurements to the MP and the PP [7].

The values of OP/PM1 show no relationship between the MP and the sagittal jaw relation. However, OP/PP1 confirmed the major connection between PP and skeletal class which is in agreement with the findings of Pyakurel [8].

Dentoalveolar differences between Angle groups were irregular [4]. However, high correlation between the OP inclination for Angle class I and III groups was noticed. This analogy can be ascribed to minor differences of the dentoalveolar structure between some Angle class I and III patients.

According to a study by Braun and Legan [9] aiming to find a geometrical link between occlusal relationship and the inclination of the OP, flattening the OP by $1.0^{\circ}$ results in approximately $0.5 \mathrm{~mm}$ backward displacement of the mandibular dental arch relative to the maxillary dental arch. Fushima et al. [1] reported a steep OP and an excessive curve of Spee are caused by a retrused and small mandible in subjects with Class II division 1 malocclusion. Different outcomes between Angle groups and skeletal groups suggest poor association between craniofacial morphology and occlusal relationships.

The correlation between these two classifications has been demonstrated in the studies of Keeling [10]. 
He evaluated the relation between several features of occlusion and craniofacial morphology in the early permanent dentition. He showed that the relation between a malocclusion severity index and skeletal morphology was weak.

Furthermore, we investigated the impact of the cant of the OP on the vertical dimension. Schudy [11] holds the view that the vertical pattern did not affect the OP inclination. This statement was confirmed by Deblock in his findings [12]. Nevertheless, Kuntz [13] and Oktay [14] rejected this theory proving that long face pattern is correlated with an important inclination of the OP. Our findings confirm these previous studies. We pointed to a strong correlation between vertical dimension and occlusal cant using three references (SN, PP, and PM). Jacobson [15] suggests that the occlusal inclination increase according to the vertical dimension. This statement has not been confirmed by additional studies. The results of our investigation demonstrated a high correlation between the orientation of the OP and open bite or deep bite, validated by Tovstein [3]. Studies revealed a decrease of the angle formed by the occlusal and the MP in subjects presenting deep bite. Celar [4] found, despite the influence of the ODI (Overbite Depth Indicator) on the OP, steeper OPs for higher ODI prevailed mostly in the higher quantiles. Tanaka and Sato [2] experiments are in line with previous results.

In the second part of the study, we are discussing the impact of orthodontic treatment on sagittal malocclusion on OP inclination. In some cases, OP cant is an expected result of the orthodontic treatment and it should be achieved with caution [16]. For class I relationship group, we must aim to keep the OP in its initial position as claimed by Tweed and Merriefield.

Regarding the influence of premolar extractions during treatment, we noticed a forward and downward rotation of OP. This finding concurs well with Yamaguchi results. He assessed the effects of extraction and non-extraction procedures on the posterior rotation of the mandible and also the OP [17]. However, this statement does not apply when extractions are made only in the upper arch.

Using elastic in class I cases does not have any influence on the OP. It can be explained by the fact that in these cases, we are using elastics. Chateau sugiests an intentional modification of the OP in class II to reduce relapse. This author claims that a slightly steep OP in this case allows a mandible growth and ensures the stability of treatment outcome. However, our results are in contrast with this earlier affirmation. It is considered as an unwanted side effect of our treatments. We noticed that the use of inter-maxillary elastics to correct class II malocclusion leads to the rotation of OP which is confirmed by an increase of OP/SN and OP/PP. This lends support to previous findings about the undesirable side effects of cl II inter-maxillary in the literature by Stallard [18] in 1933. Ellen [19] and Nelson [20] describe a vertical force that extrudes the maxillary incisors and mandibular molars, leading to the rotation of $\mathrm{OP}$ as well as a resultant opening rotation of the mandible. In line with these previous results, Janson [21] concluded that all cases using cl II elastics showed changes in OP angle. These changes have a tendency to return to the original condition and finally a forward and downward rotation of OP maintaining class II aspect. Epstein [22] studied class II cases treated with extraoral anchorage without inter-maxillary elastics and pointed out that in this type of treatment, there is no change in the OP. However, it depends on the length of the arms and the position of the headgear.

In class III cases, we noticed a significant increase of OP/PP and OP/SN also a decrease of OP/PM (more than $2^{\circ}$ ) after orthodontic treatment which does not concur well with Chateau's statement. He recommended to establish a clockwise rotation of the OP.

When we took in consideration the use of class III elastics, the effect of the treatment was significant on OP/PM compared to the cases where elastics were not used. Our findings appear to be well explained by Sign
[23]. According to this author, Class III elastics are opposite of the class II's. They promote extrusion of upper posterior teeth and lower anterior ones; the main result is a counterclockwise rotation of the OP. Treatment of class III with extractions has no impact on the OP. The value of OP/SN does not show any significant change. Raymond [24] has tried to justify applying an early treatment of class III. He explained that the main goal was the reorientation of the OP and the rehabilitation of mastication. The modification of the inclination of the OP is not always considered as a side effect. Indeed, it can be part of our treatment plan to enhance our patients smile. That's what was highlighted by Camara [25] in his studies about the "functional aesthetic OP." The average point of contact between maxillary and mandibular first molars and the upper lip stomion is taken as a reference to determine the ideal position of the incisors and enhance smile esthetics [26].

It is plausible that a couple of details could be added to refine our study: The type of elastics (Cl II or Cl III, vertical, triangular.), the duration, and observance [27]. Some protocols have been voluntarily excluded, orthopedic and orthognathic treatments [28-31]. The impact of such protocols on stability of the OP needs to be deeply investigated in the future.

\section{CONCLUSION}

This study confirmed the association between skeletal pattern and the OP inclination. The angle class appeared to have no significant influence on the OP position. This work also revealed a clockwise rotation of in class II cases and counterclockwise rotation in class III cases. Consequently, it is well-advised to be mindful of these facts before establishing any treatment plan.

\section{REFERENCES}

1. Fushima K, Kitamura Y, Mita H, Sato S, Suzuki Y, Kim YH. Significance of the cant of the posterior occlusal plane in class II division 1 malocclusions. Eur J Orthod 1996;18:27-40.

2. Tanaka EM, Sato S. Longitudinal alteration of the occlusal plane and development of different dentoskeletal frames during growth. Am J Orthod Dentofacial Orthop 2008;134:602.

3. Tovstein BC. Behavior of the occlusal plane and related structures in the treatment of Class II malocclusion. Angle Orthod 1955;25:189-98.

4. Čelar A, Tafaj E, Graf A, Lettner S. Association of anterior and posterior occlusal planes with different Angle and skeletal classes in permanent dentitions: A lateral cephalometric radiograph study. J Orofac Orthop 2018;79:267-76.

5. Raymond JL. Justification occlusale du traitement précoce de la classe III. Orthod Fr 2006;77:207-12.

6. Tropkova B, Major P, Prasad N, Nebbe B. Cephalometric landmarks identification and reproducibility: A meta analysis. Am J Orthod Dentofacial Orthop 1997;112:165-70.

7. Shen YF, Hung CH. Evaluation of occlusal plane, ala-tragion line, palatal plane and mandibular plane in Chinese. Changgeng Yi Xue Za Zhi 1988;11:218-23.

8. Pyakurel U, Thapaliya KB, Singh K, Gupta A, Gupta S, Bajracharya M, et al. Assessment of palatal plane and occlusal plane for determining anteroposterior jaw relation. INMA J Nepal Med Assoc 2019;57:3-7.

9. Braun S, Legan HL. Changes in occlusion related to the cant of the occlusal plane. Am J Orthod Dentofacial Orthop 1997;111:184-8.

10. Keeling SD, Riolo ML, Martin RE, Ten Have TR. A multivariate approach to analyzing the relation between occlusion and craniofacial morphology. Am J Orthod Dentofacial Orthop 1989;95:297-305.

11. Schudy FF. Cant of the occlusal plane and axial inclinations of teeth. Angle Orthod 1963;33:69-82.

12. Deblock L, Weissenbach O. Relations céphalométriques du plan d'occlusion. Rev Orthop Dentfacial 1997;31:393-402.

13. Kuntz M, Turlot JC, Hildwein M. The occlusal plane in Class I and Class II malocclusion: Its relation to craniofacial variables. Orthod $\mathrm{Fr}$ 1988;59:383-93.

14. Oktay. H. A comparison of ANB, WITS, AF-BF, and APDI measurements. Am J Orthod Dentofacial Orthop 1991;99:122-8.

15. Jacobson A. The "Wits" appraisal of jaw disharmony. Am J Orthod $1975 ; 67: 125-38$

16. Fourquet L, Göttle M, Bounoure G. Finishing and detailing, stability and harmony. Orthod Fr 2014;85:93-125. 
17. Yamaguchi K, Nanda RS. The effects of extraction and nonextraction treatment on the mandibular position. Am J Orthod Dentofacial Orthop 1991;100:443-52.

18. Stallard $\mathrm{H}$. The prevention of therapeutic premaxillary abstraction. Dent Cosmos 1993;75:213-33.

19. Ellen EK, Schneider BJ, Sellke T. A comparative study of anchorage in bioprogressive versus standard Edgewise treatment in Class II correction with intermaxillary elastic force. Am J Orthod Dentofacial Orthop 1998;114:430-6.

20. Nelson B, Hansen K, Hägg U. Overjet reduction and molar correction in fixed appliance treatment of class II, division 1, malocclusions: Sagittal and vertical compenents. Am J Orthod Dentofacial Orthop 1999;115:13-23.

21. Janson G, Sathler R, Fernandes TM, Branco NC, de Freitas MR Correction of Class II malocclusion with Class II elastics: A systematic review. Am J Orthod Dentofacial Orthop 2013;143:383-92.

22. Epstein WN. Analysis of Changes in molar relationships by means of extra-oral anchorage (Head-Cap) in treatment of malocclusion. Angle Orthod 1948;18:63-9.

23. Singh VP, Pokharel PR, Pariekh K, Roy DK, Singla A, Biswas KP. Elastics in orthodontics: A review. Health Renaiss 2012;10:49-56.

24. Reyes BC, Baccetti T, McNamara JA. An estimate of craniofacial growth in Class III malocclusion. Angle Orthod 2006;76:577-84.

25. Câmara CA, Martins RP. Functional aesthetic occlusal plane (FAOP). Dent Press J Orthod 2016;21:114-25.

26. Uzuner FD, Aslan BI, Dinçer M. Dentoskeletal morphology in adults with Class I, Class II Division 1, or Class II Division 2 malocclusion with increased overbite. Am J Orthod Dentofacial Orthop 2019;156:248-56.

27. Olivi P, Cheynet F, Chossegros C, Blanc JL. Orientation du plan d'occlusion et récidive postopératoire des béances antérieures. Rev Stomatol Chir Maxillofac 2009;110:269-72.

28. Dougherty HL. The effect of mechanical forces upon the mandibular buccal segments during orthodontic treatment. Am J Orthod 1968;54:83-103

29. Baek SH, Ahn HW, Yang SD, Choi JY. Establishing the customized occlusal plane in systemized surgical treatment objectives of class III. J Craniofac Surg 2011;22:1708-13

30. Antonarakis GS, Kiliaridis S, Scolozzi P. Orientation of the occlusal plane in a Class I adult population. Oral Surg Oral Med Oral Pathol Oral Radiol 2013;116:35-40.

31. Doğan S, Ertürk N. Delaire's architectural and structural cranio-facial analysis in cephalometric evaluation. Turk Ortodonti Derg 1989;2: 103-13. 